\title{
How suitable is Yahoo! Groups for school librarians' professional networking? A case study from Hong Kong
}

\author{
Samson Choi \\ Learning Resources Centre, King George V School \\ 2, Tin Kwong Road, Homantin, Kowloon, Hong Kong \\ Hong Kong \\ samson.choi@hotmail.com \\ Zvjezdana Dukic \\ Department of Information Sciences, University of Zagreb \\ Ivana Lučića 3, 10000 Zagreb \\ Croatia \\ dana.dukic@gmail.com
}

\begin{abstract}
This paper explores how members of Hong Kong based professional association of school librarians (ALESS) use Yahoo! Groups platform for their professional networking and how the platform satisfies the group's professional needs. The case study research method is applied and both quantitative and qualitative data are collected. It is revealed that ALESS members effectively use Yahoo! Groups platform even though they do not exploit all available features. ALESS members regularly use web-based mail and occasionally Files and Polls. Although some group members think that Yahoo! Groups need to be replaced with a more userfriendly tool, most respondents agree that for the time being Yahoo! Groups platform fairly fulfils ALESS group's needs. Further analysis of existing social networking software and ALESS group's needs and preferences are recommended.
\end{abstract}


Keywords: school librarians, professional networking, Yahoo! Groups

\section{Introduction}

Professional networking is vital to school librarians in digital age for staying abreast of new trends in library profession. Through professional networks school librarians share ideas, knowledges and experiences related to school librarianship, virtually and/or face-to-face. This study explores professional networking of school librarians working in English speaking schools in Hong Kong who are gathered in Association of Librarians of English Speaking Schools - ALESS. The group was established in 2001 and has been active until today. The mission of the group is to provide professional support to its members. Major aims of the group are to promote reading and information literacy, to provide professional development for members and to raise the profile of school libraries (ALESS, 2014). Group members communicate face-to-face through regular meetings and virtually through Yahoo! Groups platform.

Yahoo! Groups is a free online networking platform and it is used by millions of users from all over the world. It is the combination of web-based mailing list with archiving facilities, and services such as a homepage, files, bookmarks, photos, attachments, polls, calendar and database. The web-based mailing list is the most important feature and this function is probably the reason why many professional groups are using it. Users have to create an account at Yahoo to use some Yahoo! Group features but they can use any other email address to receive their group emails. There are two ways to post and receive messages. Members can login to Yahoo! Groups to create or read messages. Alternatively, they can send an email to group general email. All emails are archived on the Conversation page, individually under Messages and as conversation threads under Topics. There is also a search function so that group members can easily search for specific messages, files, and photos. Yahoo! Groups has also a control panel where group owner can edit the group's setting and customize features that group wants to use.

The goal of this research is to explore how ALESS group members use Yahoo! Groups for their professional networking and how the platform satisfies group's needs. Since Yahoo! Groups has been chosen by ALESS group for professional networking at the time when similar technologies were scant, one research goal is to find out why the group still uses this platform although many new types of networking software are available. 


\section{Related literature}

Online community can be defined as a virtual space where members share interests, actively participate in various activities, have access to shared resources and function in a shared social environment (Preece \& Maloney-Krichmar, 2003). Online communities may exist only in virtual space or members can meet both online and face-to- face (Tsao et al., 1999). Backstrom et al. (2008) studied online communities on Yahoo! Groups and found that group privacy and size influence members' activity within the group, that members in a small, private group are much more active from members in large, public groups.

Many studies about online communities and social networking in library field are patron or education centred (Ractham et al., 2012; Said, Tahir \& Ali, 2014; Wang et al., 2012). Social networking tools are used in libraries mainly for brand building, marketing or outreach and many evaluation studies focus on the achievement of these objectives (Mathews, 2006; Chu \& Du, 2012; Aharony 2012; Chan 2012). Outside library industry, there are social networking studies in workplace and other organizations with full time staff (Bennett et al., 2010; Van Zyl,

2009). Limited number of studies focus on professional networking among librarians (Secker, 2008; Siddique \& Mahmood, 2009; Khode, 2012) while studies about social networking among school librarians are missing. Thus, to fill this knowledge gap this paper examines social networking among members of the Hong Kong based school library association and their use of Yahoo! Groups online networking platform.

\section{Research questions}

In this study the following research questions are addressed:

Q1. How ALESS group members use Yahoo! Groups for their professional networking, i.e. what functionalities of Yahoo! Groups they use and what issues and topics they discuss and share

Q2. Why Yahoo! Groups platform remains the main communication hub for ALESS group even when other new tools are available From the RQ2 additional 2 sub-questions emerged:

Q2.1. What are ALESS group members' overall social media use habits?

Q2.2. What are specific reasons for using Yahoo! Groups platform for group communication 


\section{Methods}

The case study research method is applied in this study and both quantitative and qualitative data are collected. Data about ALESS group members' use of Yahoo! Groups platform for professional networking are extracted from the platform archives for the time period of one year, from September $1^{\text {st }} 2014$ to August $31^{\text {st }}$ 2015. Data about ALESS members' perception of suitability of Yahoo! Groups platform for professional networking and data about their general use of social networking tools are collected with an online questionnaire. The questionnaire consisted of three parts: demographic data, social media use by ALESS members and Yahoo! Groups suitability for ALESS group. Three types of questions were included: factual questions, opinion questions measured with Likert scale and open-ended questions. Data were collected with Google Form. At the time of conducting this research 127 school librarians were registered to ALESS through Yahoo! Groups platform. A total of 39 correctly filled out questionnaires were received making the response rate $30 \%$.

Participation in this study was on a voluntary basis and anonymity to all respondents was secured.

Empirical data are analyzed by applying quantitative and qualitative methods. Quantitative data about ALESS groups' use of Yahoo! Groups platform and from open-ended questions in the questionnaire are analysed by applying descriptive statistics while qualitative data from the questionnaire are analysed by conducting a conventional content analysis (Hsieh \& Shannon, 2005).

\section{Findings and discussion}

\subsection{Yahoo! Groups platform use by ALESS}

The analysis of ALESS groups' use of Yahoo! Groups shows that some features of this platform have been used through all the years, that some were used for certain period of time only and some were never used. Features that have been used all the time and are still used are About, Conversations, Files, Polls, Attachment and Photos. Further, Database and Links were used only for some time in the past and then abandoned. Events which provides a calendar of activities has never been used. Conversations is the most popular feature and probably the main reason for using Yahoo! Groups platform because it enables user to post and receive messages. In the observed time period from September $1^{\text {st }} 2014$ to August $31^{\text {st }}$ 2015 (Table 1) there were 478 sent/received messages altogether. A dynamics of sending messages differs from month to month and it depends on group events, emerging issues and, of course, on school holidays. For example, the message dramatically increase after mid- 
August when the new school year starts.

Table 1: Message frequencies on ALESS Yahoo! Group platform

\begin{tabular}{|c|c|c|c|c|c|c|c|c|c|c|c|c|c|c|}
\hline Year & Jan & Feb & Mar & Apr & May & Jun & Jul & A & & Sep & Oct & Nov & Dec & Total \\
\hline 2015 & 65 & 33 & 30 & 61 & 49 & 44 & 8 & 1 & 43 & 55 & 46 & 46 & 18 & 499 \\
\hline 2014 & 23 & 28 & 48 & 26 & 85 & 20 & 3 & 5 & 20 & 49 & 24 & 51 & 20 & 402 \\
\hline
\end{tabular}

The major topics discussed by members are Reading related activities (87 threads), ALESS administration issues (43 threads), Professional development topics (42 threads) and Collection development (36 threads). Some other topics were also discussed occasionally, all related to various school librarians' professional issues. All posts are relevant to professional work of school librarians and there are very few off-topic messages. All documents attached to messages are archived on Attachments page.

Polls are mostly used for estimating ALESS members' monthly meeting attendance and sometimes for some other purposes like selecting group coordinators. During the 2014/2015 school year seven polls were created by ALESS members and all were related to meeting attendance.

Files are not used much in the past few years. An exception is the folder "Minutes of meetings" which is regularly used to archive minutes from monthly meetings. Most folders containing professional resources are not updated for several years and the contents are most probably outdated.

Photos and links are not used for the past few years. ALESS members use a Photomatic album which has a capability of automatically archiving all photos attached to emails. During the observed period of $2014 / 2015$ school year 34 photos attached to emails were added to the Photomatic webpage.

The way ALESS group uses Yahoo! Groups platform is not a rule for all groups. There are professional groups that consider features like Links and Database very useful for professional sharing and support (Geiger, 2003).

The ALESS Yahoo! Groups usage analysis helped to answer the research question how ALESS group members use Yahoo! Groups for their professional networking. Based on the findings from the analysis, it can be concluded that Conversations are the major feature regularly used by ALESS group members and that Files and Polls are used occasionally, mostly for more administrative purposes. Other functionalities are not used and further 
research might help to explain why it is so.

\subsection{Suitability of Yahoo! Groups for ALESS group's social networking}

One of the goals of this research was to find out why Yahoo! Groups platform remains the main communication hub for ALESS group even when other new tools are available. To answer this an online survey was conducted with ALESS group inquiring about group members' habits in using various social networking software and about their perception of suitability of Yahoo Groups for their professional networking.

A demographic structure of research participants is presented in Table 2. Majority of respondents are female (89\%) and the dominant age is over 40 . All three types of school libraries are represented in similar proportion.

Table 2: Demographic characteristics of respondents

\begin{tabular}{|cc|cc|cc|}
\hline \multicolumn{2}{|c|}{ Gender } & \multicolumn{2}{c|}{ Age } & \multicolumn{2}{c|}{ Type of school library } \\
\hline Male $11 \%$ & $20-30$ & $21 \%$ & Primary school library & $34 \%$ \\
\hline Female & $89 \%$ & $31-40$ & $16 \%$ & Secondary school library & $37 \%$ \\
\hline & & $41-50$ & $39 \%$ & K12 school library & $29 \%$ \\
\hline & & 51 or above & $24 \%$ & & \\
\hline
\end{tabular}

\subsubsection{ALESS members' Social Media use habits}

Each year, global web index (GWI) interviews more than 170,000 internet users across 32 global markets on social networking behaviour (except China which is excluded because of official restrictions it places on sites like Facebook and Twitter). GWI measures three types of engagement with social platforms: account ownership (members), visitation (visited specific network in the last month) and active usage (used or contributed to the network in the last month). According to Global Web Index's (GWI) social media report summary (Mander, 2015) based on the findings from survey conducted on internet users aged 16-64, the top four most popular social networks are Facebook, YouTube, Google+ and Twitter.

Although the measurement criteria used in GWI slightly differ from criteria used in our study it is still worth comparing the findings to get an overview of social networks use by ALESS members. Social Media members and visitors counted in GWI report are compared with ALESS members who reported using social networks. Thus, the four most popular social networks from GWI report are chosen for comparing worldwide trends with ALESS members' social networks use habits (Table 3). Data from Table 3 show that ALESS members' usage rate in all four social software is higher than the membership or visitor rate for world population in GWI sample. ALESS members are particularly prevalent in using YouTube. 
Table 3: Engagement with social platforms (members and visitors vs. users)

\begin{tabular}{|c|c|c|c|}
\hline Social Media & GWI - members & GWI - visitors & ALESS - users \\
\hline Facebook & $81 \%$ & $82 \%$ & $86 \%$ \\
\hline YouTube & $60 \%$ & $73 \%$ & $86 \%$ \\
\hline Twitter & $52 \%$ & $36 \%$ & $57 \%$ \\
\hline Google+ & $60 \%$ & $29 \%$ & $69 \%$ \\
\hline
\end{tabular}

Further analysis of ALESS members' engagement with four social software looks at the purpose and the frequency of usage. Table 4 shows that most ALESS members use social software for leisure and work on daily/weekly basis. Facebook and YouTube are more extensively used for leisure and Twitter and Google+ are slightly more used for work. It is noteworthy that a lower level of professional use of some specific social software (e.g. Facebook) might be a consequence of work policy that restricts the use of software during working hours (Van Zyl, 2009).

Table 4: Engagement with social platforms (daily/weekly use)

\begin{tabular}{|c|c|c|}
\hline $\begin{array}{c}\text { Social Media } \\
\text { Facebook }\end{array}$ & $\begin{array}{c}\text { ALESS - leisure } \\
\text { daily/weekly use } \\
83 \%\end{array}$ & $\begin{array}{c}\text { ALESS - work } \\
\text { daily/weekly use } \\
43 \%\end{array}$ \\
\hline YouTube & $83 \%$ & $54 \%$ \\
\hline Twitter & $23 \%$ & $29 \%$ \\
\hline Google+ & $43 \%$ & $46 \%$ \\
\hline
\end{tabular}

To summarize, social media penetration level and usage frequency among ALESS members confirm that they are experienced in social media and are active users as well. Therefore, lack of new social software skills is not a reason for not replacing Yahoo! Group with alternative social media. Thus, it is interesting to explore other possible reasons why Yahoo! Groups remains the main online communication tool for ALESS.

\subsection{ALESS members' opinions about Yahoo Group}

To find out more about the reasons that ALESS group keeps using Yahoo! Groups for professional networking a few questions in the survey questionnaire were created to measure respondents' opinion about Yahoo! Groups features. First, ALESS members were asked to estimate how user-friendly Yahoo! Groups platform is from their own perspective; responses to this questions can be seen in Graph 1. Data show that the highest percentage 
of respondents agree that Yahoo! Groups is user-friendly while only $23 \%$ disagree with this statement. It is interesting that even $36 \%$ are neutral and the reason for choosing neutral response is unclear. A reason could be that they are not familiar with Yahoo! Groups features so they feel that they can't evaluate it or it could be that they perceive this platform neither user-friendly not user-unfriendly.

$$
\text { Agree } \quad \text { Neutral } \square \text { Disagree }
$$

Yahoo! Groups is a user-friendly tool $\quad 41 \% \quad 36 \% \quad 23 \%$

Graph 1: How user-friendly is Yahoo! Groups platform?

Furthermore, participants were asked to estimate some factors that might play a role in group's persistence in using Yahoo! Groups. This time they were asked to estimate why the group as a whole would want to keep Yahoo! Groups platform.

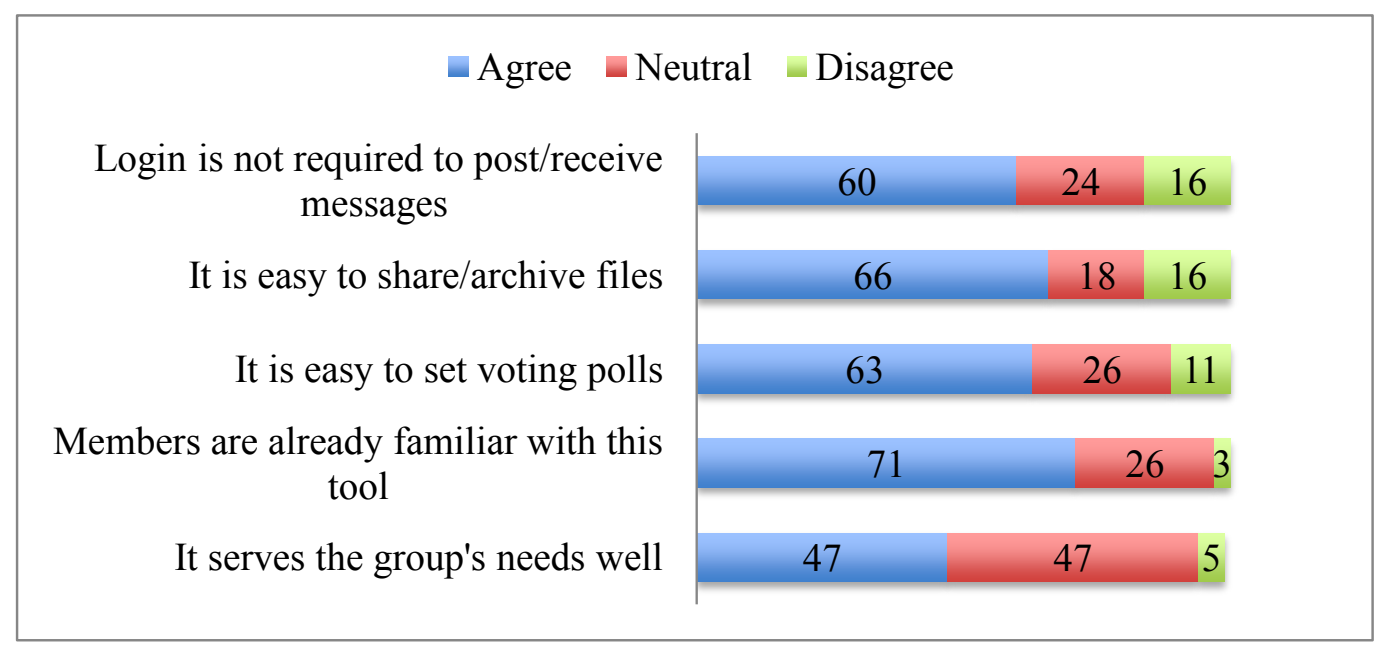

Graph 2: What are the reasons Yahoo Groups remains the main communication tool of ALESS group?

From figures in Graph 2 it can be concluded that more than half of respondents agree that Yahoo! Groups functionalities like posting/receiving messages, file sharing and setting polls are easy to use and this could be why ALESS group keeps Yahoo! Groups for professional networking. Another even stronger reason for using Yahoo! Groups from respondents' perspective might be that ALESS members are already familiar with this software and, therefore, they are hesitant to replace it with a new one. Although less than half of 
respondents think that Yahoo! Groups serves the group's needs well, only 5\% disagree with this statement. As many as $47 \%$ of respondents are neutral about Yahoo! Groups serving the needs of ALESS group but it seems that they are not ready to abandon it yet.

Resistance to change is well known and discussed in literature related to introducing new technologies in library environment (Weiner, 2003) but in the case of ALESS group it looks more like awareness of Yahoo! Groups' advantages than change resistance because findings about their use of social networking software show that they are familiar with new technologies and use them regularly for leisure and for work.

To explore ALESS members' opinions about Yahoo! Groups further two open-ended questions about advantages and disadvantages of this platform were included. There were 12 comments discussing Yahoo! Groups advantages. Respondents mostly agree that Yahoo! Groups is a good communication and sharing tool. Advantages like archiving capabilities and securing group privacy are mentioned too. Below are samples of respondents' statements:

"Group is able to communicate, share ideas, store information and use the platform as an archive." (R 6)

"It is a closed group and it has the ability to keep files archived." (R8)

ALESS members' familiarity with this tool as a reason for using is confirmed again. A respondent states:

"It has been used for many years and ALESS members are familiar with it." (R 17) Thirteen respondents provided comments about disadvantages of Yahoo! Groups. Major disadvantage mentioned by five respondents is that Yahoo account is requested for joining Yahoo! Groups and a lot of people do not use Yahoo. The following comments illustrate this opinion:

"I never use Yahoo and had to set up a separate account." (R 12)

"Not everyone is on Yahoo. Most are on Google. (R 31)

Some respondents think that they would be more active in ALESS group if some other platform were used:

"I would participate more in discussions if we were using another forum/platform." (R 12) 
Based on the analysis of ALESS members' opinions about Yahoo Groups platform it can be concluded that respondents mostly agree that Yahoo! Groups is a good platform for communication, sharing and archiving resources. This platform also secures privacy to its members and last but not least members are familiar with the tool. A major disadvantage is that members have to create Yahoo account to join and even to login if they want to post files, photos or use any other functionality except sending and receiving messages.

\subsection{Should Yahoo! Groups be replaced with another tool?}

Participants were also asked whether Yahoo! Groups should be replaced with another group discussion tool. While 32\% responded that Yahoo! Groups should be replaced with another tool only $16 \%$ were against the change. However, $52 \%$ respondents are not sure whether Yahoo! Groups should be replaced. This high percentage of respondents who are not sure about replacement indicates that a decision of replacing Yahoo! Groups with another tool is not an easy task. As mentioned earlier, respondents are aware of many advantages of Yahoo! Groups and that in case of abandoning it they would have to find a tool that would include all features that ALESS group uses in Yahoo! Groups plus some extra services that would serve the needs of ALESS. In another open-ended question those who stated that Yahoo! Groups platform should be replaced with another tool were asked to comment on their opinion and to propose a replacement tool. Three replacement tools are proposed: Facebook, Google groups and Google+.

"Facebook and Google are more common tools for users nowadays!" (R 33)

It is interesting that one respondent who supports replacement of Yahoo! Groups with another tool at the same time admits that Yahoo! Groups services such as group email list, archiving documents and setting polls, effectively serve ALESS group's basic needs.

“Yahoo! Groups serves well some basic ALESS group's needs like sending and receiving group emails, uploading resources, creating a poll." (R 17)

To summarize, for the time being most of respondents do not support replacing Yahoo! Groups with another networking software. Respondents who want to replace Yahoo! Groups with another tool are also aware of many advantages of this platform like sending emails, archiving documents, creating polls etc. They would still replace it with tools like Facebook or Google because they believe that these tools, being commonly used by ALESS members, might boost their participation. It is worth mentioning here that online software itself does not necessarily produce active and engaged online community (Bowes, 2002; Secker, 2008) and 
that a selection of suitable software depends on many factors, some technology based and some human behaviours related.

\section{Limitations of the study}

The response rate to the survey was rather low so the sample is small and might not represent well all members of ALESS group. On the other hand, findings from the survey combined with findings from ALESS group's use of Yahoo! Groups platform can be used as a starting point for a wider explorations of various available software for professional networking among school librarians.

\section{Conclusion and recommendations}

The research findings from this case study indicate that ALESS group members make good use of Yahoo! Groups platform even though they do not exploit all available functionalities. ALESS members regularly use web-based mailing list, which is considered to be the strongest feature of Yahoo Groups, They occasionally use Files and Polls as well. Although many new types of social networking software are available ALESS group still keeps Yahoo! Groups as their major communication tool. Furthermore, from the fact that ALESS members frequently use various newly developed social software it can be concluded that the lack of knowledge and skills of new technologies is not a reason for not replacing Yahoo! Group with another tool.

ALESS members mostly agree that Yahoo! Groups platform is suitable for the needs of their group and that features they mainly use are easy to use. An important argument for keeping the platform as a major communication tool is that the group has been using it for many years and members are familiar with it. A major disadvantage is that members have to create Yahoo account to join and to login to Yahoo to use some features like uploading files or creating polls.

Respondents mostly agree that Yahoo! Groups platform fairly fulfils ALESS group's needs for now and most of them do not consider replacing Yahoo! Groups with another networking software in the near future because they are concerned that another tool may not provide all existing familiar Yahoo Groups functions. Therefore, for the time being Yahoo! Groups will probably remain the main communications platform for ALESS.

The findings of this research might be useful to school librarians' professional groups in 
planning their professional networking. First, they need to examine characteristics and needs of their community, learn about their members' skills, experiences and preferences. Secondly, they need to explore capabilities of available software options and to identify features that would support group's objectives well. Researchers are advised to continue to explore professional networking in school librarianship by conducting more extensive studies on larger samples in different geographical locations.

\section{Acknowledgment}

We would like to thank to Carol Gerts, adjunct lecturer for the School of Information Studies at Charles Sturt University (Australia) for her valuable comments on the paper. 


\section{References}

Aharony, N. (2012). Facebook use in libraries: an exploratory analysis, Aslib Proceedings, 64 (4), $358-372$.

ALESS, (n.d.) ALESS (Hong Kong) - Yahoo Groups. Retrieved on 15-Apr-2015 from https://groups.yahoo.com/neo/groups/ALESS/info

Backstrom, L., Kumar R, Marlow C, Novak J, Tomkins A. (2008). Preferential behavior in online groups. Proceedings of the 2008 International Conference on Web Search and Data Mining. Palo Alto, California, USA, ACM: 117-128.

Bennett, J., Owers, M., Pitt, M. \& Tucker, M. (2010). Workplace impact of social networking. Property Management, 28(3),138-148.

Bowes, J. (2002). Building online communities for professional networks. Connecting the Future Global Summit. Retrieved March 13, 2016, from

http://unpan1.un.org/intradoc/groups/public/documents/apcity/unpan007784.pdf

Chan, C. (2012),Marketing the academic library with online social network advertising, Library Management, 33 (8/9), 479 - 489.

Chu, S. K. W. \& Du, H. S. (2013). Social networking tools for academic libraries. Journal of Librarianship and Information Science, 45(1), 64-75.

Geiger, B. F. (2003). Use of Yahoo! TM Groups for Health Education. American Journal of Health Education, 34(1), 54-55.

Graham, J.M., Faix, A., \& Hartman, L. (2009). Crashing the Facebook party: One library's experiences in the students' domain. Library Review, 58(3), 228-236.

Hsieh, H.F. \& Shannon, S.E. (2005). Three Approaches to Qualitative Content Analysis, Qual Health Res 15(9),1277-1288.

Khode, S. (2012). Use of Various Mailing Lists by Library Professionals in India: A Study. International Journal of Information Research, 2(2), 189-206.

Mathews, Brian S. (2006) "Do You Facebook? Networking with Students Online," College \& Research Libraries News 37 (5), 306-307 
Mander, J. (2015) GWI Social Media Summary Q4 2014 Retrieved on 22nd April 2015 from http://www.globalwebindex.net/

Preece, J., \& Maloney-Krichmar, D. (2003). Online communities: focusing on sociability and usability. Handbook of human-computer interaction, 596-620.

Ractham, P., Kaewkitipong, L., \& Firpo, D. (2012). The Use of Facebook in an Introductory MIS Course: Social Constructivist Learning Environment*. Decision Sciences Journal of Innovative Education, 10(2),165-188.

Said, M. N. H. M., Tahir, L. M., \& Ali, M. F. (2014). Facebook as a Tool: Exploring the use of Facebook in Teaching and Learning. In Teaching and Learning in Computing and Engineering (LaTiCE), 2014 International Conference on (pp. 120-124). IEEE.

Secker, J. (2008), Case Study 5: Libraries and Facebook, LASSIE: Libraries and Social Software in Education, London: Centre for Distance Education, University of London, Retrieved on 22nd January 2016 from http://citeseerx.ist.psu.edu/viewdoc/download?doi=10.1.1.174.617\&rep=rep1\&type=pdf

Siddique, N. \& Mahmood, K. (2009). The Role of Mailing Groups in the Development of the Library Profession in Pakistan: the case of plagpk. Information Development, 25(3), 218-223.

Tsao, R., Preece, J. \& Lazar, J. (1999). One Foot in Cyberspace \& the Other on the Ground. A Case Study of Analysis and Design Issues in a Hybrid Virtual and Physical Community. WebNet Journal: Internet Technologies, Applications \& Issues, 1(3), 49-57.

Van Zyl, A. S. (2009). The impact of Social Networking 2.0 on organisations. The Electronic Library, 27(6), 906-918.

Wang, Q., Woo, H. L., Quek, C. L., Yang, Y., \& Liu, M. (2012). Using the Facebook group as a learning management system: An exploratory study. British Journal of Educational Technology, 43(3), 428-438.

Weiner, S. G. (2003). Resistance to Change in Libraries: Application of Communication Theories. Libraries and the Academy, 3(1), 69-78. 


\section{Biographical notes}

Mr. Samson Choi holds a master degree in Information Studies from Charles Sturt University, Australia. He worked in special library in Hong Kong. Currently, he works as Academic Information Coordinator in King George V School, ESF, Hong Kong and he is also the committee member of Hong Kong Library Association. His research interests focus on virtual community, user studies, information behaviours, new technologies in information science and education.

Dr. Zvjezdana Dukic holds a PhD in Library and Information Science from the University of Zagreb, Croatia. She worked in academic, special and school libraries in Croatia, United Kingdom and Hong Kong. She also taught courses in the area of library and information management at The University of Hong Kong. Presently she is a part-time lecturer at the Department of Information Sciences, University of Zagreb. Her research interests focus on application of new technologies in library services and users' education. She has been giving presentations in many international conferences, published papers in international journals and also received several international awards for her work in school libraries in Hong Kong. 